\title{
Qualificando Futuros Professores DE Sociologia
}

\author{
Luiza Helena Pereira ${ }^{1}$
}

\begin{abstract}
RESUMO
Este artigo relata o trabalho realizado na disciplina "0 Ensino da Sociologia no Ensino Médio", oferecida pelo Departamento de Sociologia da Universidade Federal do Rio Grande do Sul. Relata o motivo da criação da disciplina e a síntese de sua proposta: auxiliar os alunos da graduação em Ciências Sociais a pensar como ensinar sociologia para alunos do nível médio. Apresenta a discussão sobre as finalidades da sociologia no ensino médio, temas a ser estudados e como trabalhar estes temas. 0 objetivo geral da disciplina é qualificar os alunos da graduação para adequar o conhecimento recebido no Curso de Ciências Sociais para o ensino da sociologia em nível de escola secundária.

Palavras-chave: Qualificação de professores. Professores de sociologia. Sociologia no ensino médio
\end{abstract}

\begin{abstract}
This article is about teaching sociology in high school. It describes why, what and how to teach sociology at this level. The course aims to qualifyng future teachers to teach sociology to students in secundary schools.

Key words: Qualifyng teachers. Sociology teachers. Sociology in high school.
\end{abstract}

\section{A CRIAÇÃo DA DISCIPLINA}

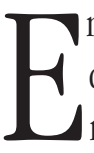
ntre 1993 e 1994 os professores do curso de Ciências Sociais da Universidade Federal do Rio Grande do Sul promoveram um intenso processo de rediscussão e reformulação do currículo deste Curso. 0 processo envolveu alunos, professores dos três departamentos, Antropologia, Ciência Política e Sociologia e professores de outros departamentos que oferecem disciplinas para este Curso.

Naquele momento, principalmente os alunos reivindicavam disciplinas oferecidas pelo curso de Ciências Sociais, como complemento à Licenciatura. Disciplinas lecionadas por professores de Ciências Sociais, como apoio à prática educativa dos mesmos. Em outras palavras: os alunos sentiam que precisavam, para ensinar ciências sociais, de

\footnotetext{
${ }^{1}$ Professora do Departamento de Sociologia da Universidade Federal do Rio Grande do Sul.
} 
maior preparo, fornecido pelo curso de origem, além do apoio das disciplinas da Faculdade de Educação. Naquela ocasião foi consenso entre os departamentos, professores e alunos introduzir no currículo a disciplina: 0 Ensino da Sociologia no Ensino Médio a ser lecionada pelo Departamento de Sociologia. Em 1997 a disciplina foi implantada, na prática, cabendo-me a tarefa de ser a professora responsável pela mesma.

A disciplina é oferecida todo semestre alternando horário para o diurno e para o noturno, a fim de possibilitar a todos os alunos o acesso a ela. A turma da noite tem sempre mais alunos que a do diurno. No primeiro dia de aula realiza-se uma enquete a fim de traçar o perfil da turma. Os dados do perfil, quando apresentados para todos os alunos, revelam que eles estudam juntos, mas nem sempre se conhecem. A enquete ao aluno tem como objetivo demonstrar aos alunos: 1. o perfil da turma com a qual convivem; 2. a importância de eles também fazerem o perfil dos seus futuros alunos do ensino médio, para melhor conhecê-los e ao mesmo tempo propiciar que toda a turma venha a se conhecer. A enquete deve conter perguntas referentes ao interesse pessoal dos alunos como: o que gostam de fazer como lazer, músicas preferidas, leitura, TV, filmes e demais atividades. Estes dados, além de fornecer informações sobre os alunos, permitirão definir assuntos e tarefas para o ensino da sociologia.

0 resultado das enquetes realizadas ao longo dos dez anos trabalhados nesta disciplina permite afirmar que em sua maioria os alunos que cursam a disciplina 0 Ensino da Sociologia no Ensino Médio são do sexo feminino, possuem entre 20 a 24 anos, são solteiros, trabalham e estudaram tanto em escola pública quanto particular (quase sempre há a mesma proporção de indivíduos nas duas situações). Os alunos do Curso de Ciências Sociais da Universidade Federal do Rio Grande do Sul concluem, em sua maioria, as duas habilitações oferecidas: bacharelado e licenciatura.

$\mathrm{Na}$ enquete solicita-se que os alunos indiquem temas para analisarem na disciplina 0 Ensino da Sociologia no Ensino Médio. Ao fazer esta pergunta tem-se como princípio que há necessidade de dar voz aos alunos. Mas, embora contemplando as sugestões dos alunos, considera-se que o professor deve ter um norte para ministrar a disciplina sob sua orientação, que deve ter firmeza e manter a coerência sobre temas e metodologia para ensinar a sociologia na escola média. Mais adiante nos deteremos mais neste comentário.

0 objetivo geral da disciplina é qualificar os alunos da graduação para adequar o conhecimento recebido no Curso de Ciências Sociais para o ensino da sociologia em nível de escola secundária.

Para tanto a disciplina propõe: 1. Conhecer a legislação sobre o médio no Brasil e o ensino da sociologia, seus objetivos, funções, a Lei de Diretrizes e Bases da Educação Nacional (LDB), os parâmetros e as diretrizes curriculares; 2. Analisar a importância 
(finalidades) de ensinar sociologia para os alunos do Ensino Médio, em nosso País; 3. Refletir sobre parâmetros para selecionar temas emergentes da sociedade brasileira e de diferentes sociedades que possam ser de interesse dos alunos de ensino médio; 4. Conhecer o estado atual do ensino da Sociologia no Ensino Médio, em Porto Alegre e Rio Grande do Sul, com informaç̧ões sobre este ensino no Brasil; 5. Investigar as diversas concepções teórico-metodológicas propostas por autores da sociologia e aquelas presentes nos livros didáticos, nos programas de ensino e na prática social de professores de Sociologia do Ensino Médio; 6. Compreender as necessidades e as possibilidades de transformação das condições de ensino da Sociologia no Ensino Médio, contemplando a análise das alternativas de transformação da sociedade brasileira.

A intenção deste artigo é explanar sobre a rica experiência em ministrar esta disciplina e sugerir sua implantação em cursos de Ciências Sociais para qualificar e unificar, dentro da diversidade, a formação dos futuros professores, que ocupação a importante tarefa de levar aos jovens brasileiros o conhecimento e a prática da sociologia.

Este artigo apresenta os objetivos da disciplina 0 Ensino da Sociologia no Ensino Médio, o conteúdo programático, a metodologia de trabalho com os alunos da graduação em Ciências Sociais, a bibliografia sugerida na disciplina, bem como seus resultados. Neste artigo esta discussão está mesclada e se interpenetrará nos vários tópicos apresentados de forma dialética ${ }^{2}$, pois se a forma de exposição pode ser didaticamente organizada não é isto que acontece no dia-a-dia da sala de aula, onde não existe uma linearidade no processo de ensino-aprendizagem.

\section{Por QUe SOCIOLOGIA NO ENSINO MÉDIO?}

Esta questão é considerada a questão-chave, norteadora de todo conteúdo programático abordado na disciplina 0 Ensino da Sociologia no Ensino Médio. Escolheu-se esta pergunta para ser a desencadeadora da motivação para pensar na sociologia para alunos do ensino médio.0s alunos do curso de Ciências Sociais trazem consigo uma série de dúvidas, ao ingressar na disciplina, sendo uma delas a questão indicada. Esta questão é geradora, também, da intenção em demonstrar a estes alunos que devem ter bem claro a importância do ensino da sociologia no nível médio e que devem passar ao aluno secundarista esta certeza e a clareza desta importância. Além disso, esta também é uma pergunta que a sociedade se faz, após a inserção da sociologia na LDB de 1996 e, principalmente, com a divulgação do Parecer 38/2006 aprovado em 07 de julho de 2006 (BRASIL, 2006b).

\footnotetext{
${ }^{2}$ A bibliografia utilizada na disciplina, por exemplo, estará inserida no texto e sobre ela será feito um comentário pois fica desarticulada do todo, se apresentada em separado.
} 
Começa-se o semestre apresentando a disciplina para os alunos. Deixa-se claro que o trabalho abrangerá dois níveis: 1- 0 primeiro diz respeito a temas e leituras que orientarão nossa reflexão acerca do porquê (finalidades), o que (conteúdos) e de como (metodologia) ensinar sociologia no ensino médio, no Brasil, sendo estes temas destinados aos alunos do Curso de Ciências Sociais; 2- o segundo nível diz respeito a temas, atividades, exercícios, leituras, que poderão ser trabalhados com os alunos do ensino médio. Os dois níveis expressam temas de discussão, desencadeados com os alunos do Curso de Ciências Sociais, que sugerimos ser apreciados com os alunos do ensino médio.

Neste momento já se introduz a discussão sobre 0 ensino médio no Brasil. Para acercar-se deste conhecimento analisamos os objetivos e funções, o currículo e as diretrizes curriculares (Brasil, 1996; 1998a, 1998b; 2000; 2006a, 2006b). Pondera-se ainda o papel das humanidades no currículo do ensino médio brasileiro e realiza-se uma análise crítica da LDB. Esta é obtida através do conhecimento acerca da correlação de forças em jogo quando da concepção da LDB, em 1996 (SAVIANI, 1997).

Indica-se, também aos alunos, efetuar a comparação entre a LDB e o texto de Durkheim "Educação e Sociologia". A intenção é salientar a proximidade entre os dois textos quanto: a definição e a concepção de educação (princípios, fins, função da educação); a organização dos currículos para Durkheim e a proposta de organização dos currículos da educação básica, na LDB (base, caráter, condições); o papel da sociologia na LDB comparado com a afirmação do caráter social da educação e o papel da sociologia, para a pedagogia em Durkheim (DURKHEIM, 1978).

Dando prosseguimento ao programa, propõe-se aos alunos o exame da sociologia no ensino médio no Brasil. Inicialmente apresenta-se o histórico da implantação da sociologia no ensino médio de 1890, com Benjamin Constant até o momento atual, no caso presente, quando da aprovação do Parecer 38/2006 (BRASIL, 2006b; CARVALHO, 2004; FERNANDES, 1958; MEKSENAS, 1994; MORAES, 2003).

Informa-se das pesquisas realizadas no Brasil sobre o tema, com base nos anais de congressos da Sociedade Brasileirade Sociologia (SBS) eda Federação Nacional dos Sociólogos do Brasil (FNSB). Relata-se sempre a situação em que se encontra, no momento do curso, a implantação da sociologia nas escolas secundárias, no Brasil e, em particular no Rio Grande do Sul. Esta situação remete ao conhecimento da luta dos sociólogos ${ }^{3}$, através de suas instituições para implantar e agora consolidar esta disciplina nas escolas brasileiras.

\footnotetext{
${ }^{3}$ Esta luta sempre foi conduzida pelas instituições representativas dos sociólogos, entre as quais a Federação Nacional dos Sociólogos-Brasil (FNSB), vários sindicatos estaduais, dentre os quais o Sindicato dos Sociólogos do Rio Grande do Sul (SINSOCIÓLOGOS-RS) e o de São Paulo (SINSESP), entre outros, a Sociedade Brasileira de Sociologia (SBS) em conjunto com Universidades de nosso país, entre as quais destaca-se a Universidade Federal do Rio Grande do Sul (UFRGS).
} 
Na continuidade das atividades apresenta-se o tópico 0 professor e os alunos. Discute-se a condição de ser professor; a diferença entre ensinar e aprender/conhecer, a relação entre professor e aluno e, a difícil tarefa da avaliação. Isto porque se entende que o professor de sociologia deve cuidar para que a sociologia seja sempre uma disciplina que encante o sujeito que a está conhecendo. Que ela não deve jamais se distanciar do interesse dos alunos de ensino médio, sob pena de não cumprir com seus objetivos.

Em primeiro lugar informa-se aos alunos a situação do ensino médio no Brasil, através da pesquisa de Miriam Abramovay e Mary Garcia Castro, denominado Ensino Médio: múltiplas vozes. Considera-se importante que os alunos das Ciências Sociais conheçam a realidade dos alunos e professores do ensino médio. Implica em saber sobre as diferenças sociais nas escolas públicas e privadas, a situação dos recursos humanos e materiais, os indicadores do chamado fracasso escolar, a extensão da exclusão digital, as relações sociais na escola, o acesso a cultura e a internet, constatando as representações que os alunos e os membros do corpo técnico pedagógico fazem sobre a reforma do ensino médio (ABRAMOVAY; CASTRO, 2003).

Sugere-se a idéia do professor como sujeito de transformaç̧ão se opondo a condição do sujeito que nega a realidade em que está inserido (VASCONCELLOS, 2003). 0 professor deve entender o ensino e a avaliação, por exemplo, como aspectos do processo de aprendizagem que merecem o maior cuidado. Acreditamos que o professor de sociologia deve ter uma postura de sociólogo-professor e assim aplicar o que aprendeu em seu curso de Ciências Sociais. Como aprendeu a pesquisaré um pesquisador, portanto deve ser um professor-pesquisador e não simplesmente um reprodutor de idéias. É importante auxiliar 0 aluno a desconstruir e reconstruir o conhecimento, considerando a sala de aula como um espaço de estudo e de pesquisa. É imprescindível ter bem claro que a avaliação é um fato cotidiano, um ato do dia a dia e não o resultado formal do ensino expresso num determinado momento do aprendizado. Os futuros professores devem se pautar pela democratização da avaliação (DEMO, 2004).

Continuando o programa planejado, parte-se para a discussão do tema central da disciplina: A sociologia no Ensino Médio: finalidades, o que ensinar e como ensinar sociologia para os jovens secundaristas que não estão na escola para aprender sociologia como profissão.

\section{FINALIDADES DO ENSINO DA SOCIOLOGIA NA ESCOLA SECUNDÁRIA}

Em relação a finalidades do ensino da sociologia na escola secundária perguntase por quêensinar sociologia? Afirmamos com Wright Mills que a sociologia deve ajudar 
a desenvolver, no educando, o que este autor denominou de "imaginação sociológica" (MILLS, 1969). Embora possa parecer óbvio, enfatiza-se que a sociologia permite compreender a relação indivíduo-sociedade, pois é ela que estabelece uma explicação mais direta do que acontece com cada um de nós e a organização da sociedade mais ampla - família, gênero, religião, violência, trabalho, saúde, poder social, político e econômico. Como afirma Wright Mills, a sociologia permite estabelecer a ligação entre a biografia, a história e a relação entre ambas dentro da sociedade (MILLS, 1969).

Para responder esta pergunta, por quê estudar sociologia, sugere-se, ainda, a leitura de Giddens, Elias, Coulson e Riddel, Enno Liedke Filho, Sérgio Adorno, Charles-Henry Cuin e Gresle François e Immanuel Wallerstein. Com estes autores compreendemos que a reflexão sociológica ocupa um papel central para conhecer as forças sociais que transformam os dias de hoje. Os autores informam que muitos conceitos criados nas ciências sociais já fazem parte do dia-a-dia dos agentes sociais. Como exemplo são citados conceitos como classes sociais, a noção de estado, soberania, política, marginalidade, exclusão social, entre outros. Ensinar sociologia, portanto, é auxiliar os jovens estudantes do ensino médio decifrar estes conceitos e entender as relações que se estabelecem no cotidiano de suas vidas (GIDDENS, 2001; ELIAS, 1999; COULSON; RIDDEL, 1979; LIEDKE FILHO, 2004; ADORNO, 1997; CUIN; GRESLE, 1994; WALLERSTEIN, 2002)

Neste tópico discute-se ainda a relação entre senso comum e o conhecimento científico. Com Bourdieu, em 0 ofício do Sociólogo, reinterpretamos suas lições referentes à pesquisa social e a entendemos como lições para um professor. Assim, argumentamos com os alunos sociólogos que eles, como futuros professores de sociologia, devem ter presente as lições de Bourdieu, para poder auxiliar o aluno, aprendiz da sociologia a diferenciar objeto real, pré-construído pela percepção, de objeto científico, um sistema de relações expressamente construído.

São lições da aula, agora para o aprendiz de professor de sociologia, ele irá auxiliar o jovem aluno do ensino médio a realizar a ruptura, ou seja entender a sociedade sem a ilusão da transparência, o que significa evitar explicar a vida social pela concepção que dela fazem aqueles que participam da vida social. Não será através do depoimento ou opinião de pessoas que se poderá explicar a realidade social em que o estudante está inserido.

O futuro professor de sociologia poderá auxiliar a desenvolver, no aluno adolescente, o princípio da não-consciência, ou seja, evitar explicar as representações dos sujeitos independentes das relações objetivas nas quais estão inseridos. Este princípio é para os alunos de Ciências Sociais incorporar em sua profissão de sociólogo. Não faz parte do conhecimento a ser transmitido como conteúdo teórico aos alunos do ensino médio. 
Sugere-se que, como professor, os alunos da graduação em Ciências Sociais devem submeter sua prática sociológica (pedagógica) à razão epistemológica para definir e inculcar uma atitude de vigilância em seu trabalho de professor: verificar constantemente se o que está trabalhando com os alunos do ensino médio faz parte de sua realidade, é de seu interesse, tem sentido para eles, se enfim, a sociologia não está ininteligível para os alunos. 0 jovem aprendiz de professor deve lembrar, com Bourdieu, que há a teoria do conhecimento sociológico e a teoria do sistema social. Ele, jovem aprendiz de professor e de sociólogo, deve saber o ofício do sociólogo, a interiorização dos princípios da teoria do conhecimento sociológico. Eles, seus alunos do ensino médio devem somente aprender a entender a sociedade.

Em relação ao senso comum postula-se que o aluno de Ciências Sociais entenda o mesmo como uma forma de conhecimento e em suas aulas realize a dialética de partir do senso comum em busca de um conhecimento mais elaborado. Adiante, no tópico referente à metodologia abordaremos com mais detalhe este tema.

\section{O QUE ENSINAR EM SOCIOLOGIA NO ENSINO MÉDIO. QUAL SOCIOLOGIA?}

É hora de retomar o que foi prometido na introdução, quanto à firmeza e a coerência que o professor de sociologia deve ter ao selecionar temas para ensinar na escola média. Postula-se, comumente, que se deve trabalhar temas sugeridos pelos alunos do ensino médio, para manter seu interesse sob pena de a sociologia ficar abstrata, teórica e desvinculada da realidade. Mas convenhamos, se a sociologia é o estudo da realidade social como pode permanecer desvinculada da mesma?

Em relação à seleção dos temas para serem estudados em sociologia no ensino médio, argumentamos que há parâmetros que devem ser respeitados. Pensa-se que 0 professor de sociologia deve ouvir, sim, os alunos sobre temas de seu interesse. Mas, em aula sempre enfatizamos, não deve a sociologia tornar-se um estudo de problemas brasileiros (à semelhança da disciplina de Estudos de Problemas Brasileiros, que muitos de nós tivemos em nossos cursos de graduação). Em outras palavras: ao coletar os temas de interesse dos alunos, o professor de sociologia se depara com uma diversidade de temas, aparentemente desconexos entre si: violência, trabalho, desemprego, aborto, drogas, e outros tantos que os alunos secundaristas costumam sugerir para estudo. Bem, então, o que fazer?

Costumamos dizer que há questões sociológicas e questões-chaves em sociologia que devem ser consideradas. Com Weber relembramos que a seleção de temas para a pesquisa (no caso para o ensino) deve estar vinculada aos temas chaves da época em que 
o indivíduo vive. É uma seleção baseada em valores. 0 objeto de estudo (pesquisa ou ensino) édeterminado pelas idéias evalores do investigador e de sua época (Weber, 1967). Com Marx aprendemos que a sociedade deve ser analisada quanto à sua estrutura e a dinâmica sempre em movimento e contradição (Marx, 1971b). Com Durkheim (1995)verificamos que os fatos sociais são objeto de estudo da sociologia.

Apartir da leitura de Wright Mills (1969, p.14) discute-se a diferença entre questões individuais, privadas pessoais, que são perturbações originadas no meio mais próximo, e questões públicas, sociais, que dizem respeito à estrutura social. Esta última, sim, objeto de explicação sociológica.

Lembra-nos ainda este autor, remetendo a Marx, Durkheime Weber que "quaisquer que sejam os problemas específicos dos analistas sociais clássicos, por mais limitadas ou amplas as características da realidade social que examinaram, os que tiveram consciência imaginativa das possibilidades de seu trabalho formularam repetida e coerentemente três séries de perguntas": Resumidamente são elas: 1) a estrutura da sociedade, 2) a posição da sociedade na história humana e3) que variedades de homens predominam na sociedade e no período estudado (MILLS, 1969, p. 13).

Advertimos ainda que os temas podem ser os mais variados possíveis, como exemplo indica-se obra tão diversa como a de Bourdieu (1988, p. 44).que realizou estudos sobre educação, fotografia, agentes sociais, gosto, arte, alta costura, família, poder. Em suas Lições de aula Bourdieu refere que "a sociologia é a arte de pensar coisas fenomenicamente diferentes como semelhantes em sua estrutura e seu funcionamento, e de transferir o que foi estabelecido a propósito de um objeto construído, por exemplo o campo religioso, a toda uma série de novos objetos, o campo artístico, o campo político, e assim por diante".

Com estas referências enfatizamos que os mais variados temas podem ser objeto de estudo da sociologia, mas há que traçar uma rede conectando os temas uns aos outros. Esta rede é a fina malha da estrutura social, da organização da sociedade. 0 professor de sociologia deve auxiliar o aluno a construir a estrutura de relações que organizam a sociedade.

Indicações de temassão também encontrados em Giddens (2001, 2005). Este último discute temas desde: 0 que é sociologia, também questões mais estruturais como trabalho, globalizaçã̃o, classes, estratificação, desigualdade até questões mais cotidianas, como familia, interação social e vida cotidiana, algumas das quais ainda pouco analisadas em sociologia como comunicação não-verbal, rosto, corpo e discurso em interação. São apresentados, também, temas que merecem muita atenção na realidade atual e sugere-se que possam também ser trabalhados com alunos do ensino médio. São eles: asociologia do corpo: saúde, doença e envelhecimento, gênero e sexualidade, crise ecológica, entre outros. 
Estes princípios orientadores da seleção de temas estão imbricados com a metodologia de ensino da sociologia, que passaremos a comentar. Da mesma forma a mais recente: Orientações Curriculares para o Ensino Médio - conhecimentos de sociologia, de 2006 é trabalhada enquanto sugestão de temas e de metodologia de trabalho.

\section{COMO ENSINAR SOCIOLOGIA NO ENSINO MÉDIO?}

Este título remete para a análise das orientações teóricas e metodológicas no ensino de sociologia e para a prática da pesquisa em sociologia na sala de aula. Insistimos, com os alunos da graduação em Ciências Sociais, que metodologia não significa técnicas de lecionar. Há concepções teóricas-metodológicas no ato de ensinar. Significa que estes alunos devem buscar embasamento teórico para escolher sua forma de ensinar.

Um dos pontos ressaltados, a partir do aprendizado legado pelos clássicos da sociologia, é que um dos instrumentos metodológicos, por excelência, da sociologia é a comparação (DURKHEIM, 1995; MARX, 1971b; WEBER, 1967, BOURDIEU, 1994, 1988). Trabalhar com a comparação, com alunos do ensino médio resulta em exercício não só de escalar níveis superiores de conhecimento, como também auxilia a entender a realidade de forma mais organizada e mais concreta.

Quando enfatizamos a intenção da sociologia em auxiliar os alunos da escola secundária a entender a realidade como uma teia de relações, já estamos manifestando que neste ato há a transposição do senso comum para um conhecimento mais organizado. Volta-se aqui ao tema do senso comum, como prometido.

Postulamos com Gramsci que o saber do senso comum é o primeiro nível de concretude do conhecimento. Partindo-se da problematização (concreto) busca-se a teorização (abstração), chegando ao bom senso (concreto) (GRAMSCI, 1978). Ou ainda, como dizia Marx: o movimento de investigação parte do concreto real (caótico) busca as leis mais gerais (conceitos, teorias, abstrato) e volta ao concreto, agora entendido como o real pleno de múltiplas relações e determinações (MARX, 1971a, 1971b).

Neste movimento do concreto ao abstrato e de volta ao concreto, através da comparação estamos reivindicando, com Bourdieu (1988, p. 43) que "a própria leitura dos dados cotidianos pode tornar-se um ato científico".

Sugerimos ainda, aos alunos das Ciências Sociais, tomar conhecimento da teoria da metodologia da problematização, método utilizado por Paulo Freire, também compartilhado por Meksenas (1994) e Berbel (1999) apontado com base nos trabalhos teóricos de Gramsci e Charles Maguerez, entre outros. Esta metodologia, embora inovadora nas escolas brasileiras, não o é em termos de princípios, pois esses podem ser encontrados em teóricos clássicos como Sócrates, Marx, Dewey. 
Abrimos um tópico especial para discutir a pesquisa em sociologia na sala de aula. Para leitura indicamos Marcos Bagno e Giddens. Bagno nos mostra, com clareza, a importância que professor ao solicitar uma pesquisa aos seus alunos assuma a atitude de um professor orientador da pesquisa. Guiar o aluno para projetar o estudo (construir um projeto de pesquisa) significa: escolher o tema, justificar esta escolha, realizar leituras sobre o tema (revisão da bibliografia), construir um problema, traçar os objetivos, buscar explicações já existentes (quadro teórico), lançar pressupostos de explicação (hipóteses), definir como vai pesquisar (metodologia e técnicas). Por fim, explicitar os resultados da investigação (BAGNO, 2003; GIDDENS, 2005).

Para nós, sociólogos, esta tarefa é bem conhecida. Acreditamos que os futuros professores de sociologia são plenamente capazes de orientar os alunos do ensino médio na investigação da realidade e depois na exposição desta investigação, pois foram formados neste métier. Tarefas que, mais do que tarefas sociológicas, são formas de auxiliar os jovens adolescentes a organizar seu pensamento, buscar informações, concluir, enfim éo desenvolvimento do raciocínio lógico e abstrato que estamos sugerindo.

\section{Concluindo}

Para concluir nossa sugestão para 0 ensino da sociologia no ensino médio ressaltamos que um tópico especial é trabalhado no final do semestre Este trata da realidade do ensino da Sociologia nas escolas secundárias de Porto Alegre e do Rio Grande do Sul

Este tema serve para mostrar aos alunos das Ciências Sociais a situação do ensino da Sociologia nas escolas secundárias de Porto Alegre, e do Rio Grande do Sul (RS), fazendo referência ao Brasil, como um todo. Este é o tema da pesquisa que desenvolvo. Apresentamos aos alunos o número de escolas da rede escolar do RS. Destacamos as que já apresentam a sociologia em seu currículo. Informamos o número de professores de sociologia e destes, quantos são formados em Ciências Sociais e quantos são formados em outros cursos como filosofia, pedagogia, história, entre outros ${ }^{4}$. Propomos, ainda, aos alunos a análise de alguns programas de ensino praticados na rede escolar do RS (PEREIRA, 2001a, 2001b, 2001c, 2004, 2005a, 2005b).

Ressaltamos que a bibliografia, no final deste artigo é aquela trabalhada na disciplina. Nem sempre a mencionamos em sua totalidade neste texto, mas resolvemos deixá-la na íntegra, pois poderá auxiliar os futuros professores de sociologia a balizarem sua escolha de textos a ser trabalhados. A bibliografia, assim como o trabalho desenvolvido

${ }^{4}$ No levantamento realizado em 2006, verificou-se que de 441 professores de sociologia do ensino médio somente 15,5\% são formados em Ciências Sociais. 
na disciplina 0 Ensino da Sociologia no Ensino Médio, apresenta dois níveis: aquela direcionada para os alunos de Ciências Sociais e aquela sugerida a ser trabalhada com alunos do ensino médio. Finalmente instruí-se os alunos que não é recomendável a adoção de um manual de sociologia como cartilha de trabalho. 0 uso de apenas um livro-texto empobrece a infinita e rica diversidade do real.

Mais um comentário. Quando sociólogos se reúnem para discutir o que ensinar na escola secundária, um tema sempre é abordado: deve-se ensinar os clássicos aos alunos do ensino médio? Deixamos aqui nossa certeza de que os clássicos não devem ser ministrados na forma de conteúdo aos alunos do ensino médio. Os clássicos estudaram a sociedade recortando aspectos finitos (objeto) frente à infinita complexidade do real (Weber, 1967), construindo uma forma de investigação (método) e de explicação próprios, de acordo com a sua forma de ver o mundo, quer seja como uma sociedade com solidariedade social (Durkheim, 1995), quer seja uma sociedade contraditória (Marx, 1971a, 1971b), quer seja uma sociedade onde vigora os interesses e a dominação (Weber, 1967).

Assim sendo, voltamos a frisar que os alunos do ensino médio podem e devem conhecer os clássicos da sociologia, não como conteúdos a serem absorvidos, mas sim como eles são: autores clássicos, que fundaram uma ciência, um campo de conhecimento com objeto e método próprios, realizaram o estudo da realidade social e nos propiciam até hoje, a possibilidade de recorrer a eles para entender sociedade atual. Desta forma é que devem ser conhecidos Émile Durkheim, Karl Marx e Max Weber por todos estudantes da sociologia.

Como trabalho final da disciplina o ensino da sociologia no ensino médio é solicitado aos alunos de Ciências Sociais a elaboração de um pré-programa de sociologia para o ensino médio. Este consiste no pré-planejamento de suas futuras aulas, como se já tivesse assumido uma turma de jovens do ensino médio. 0 programa deve contemplar um ano letivo e nele o aluno de Ciências Sociais deverá abordar: quem é o aluno do ensino médio, qual a situação-realidade vivenciada nas escolas, qual a situação do ensino médio e do ensino da sociologia em nosso estado, país. 0 programa deve ser planejado para um ano letivo, dividido em três trimestres, com duas/horas aula por semana. É necessário definir tema(s) e justificar. Propor métodos e justificar. Levar em consideração a análise teórica que realizamos na disciplina. Escolher no programa um tópico e operacionalizá-lo (em algumas aulas), o que significa descrever como vai trabalhá-lo através de exemplos concretos (nomear e colocar o exemplo no trabalho de músicas, filmes, poesias, livros, textos, exercícios, pesquisa social). Comentar e posicionar-se sobre a possibilidade de incluir a pesquisa social em sala de aula. 
Este trabalho depois de analisado deveráse constituir naúltima e mais importante avaliaçã̃o do semestre.

Esperamos que este artigo contribua para qualificar a formação dos licenciandos em Ciências Sociais e sirva de reflexão para seus futuros projetos de sociólogo-professor.

\section{REFERÊNCIAS}

\section{* Textos recomendados:}

ABRAMOVAY, Miriam; CASTR0, Mary Garcia. Ensino Médio: múltiplas vozes. Brasília: UNESCO/MEC, 2003.

BAGNO, Marcos. Pesquisa na escola: o que é, como se faz. 3. ed. São Paulo: Edições Loyola, 2003.

BERBEL, Neusi Aparecida Novas (Org.). Metodologia da Problematização: fundamentos e aplicações. Londrina: UEL, 1999.

BOURDIEU, Pierre et al. El ofício de sociólogo. 3. ed. México: Siglo Veintiuno, 1994.

BOURDIEU, Pierre et al. Lições da aula. São Paulo: Ática, 1988.

BRASIL. Lei No 9.394, de 20 de dezembro de 1996. Lei de Diretrizes e Bases da Educação Nacional. Brasília: Ministério da Educação, 1996.

BRASIL. Ministério da Educação. Secretaria de educação Básica. Orientações Curriculares para o Ensino Médio. Ciências Humanas e suas Tecnologias. Brasília, 2006a.

BRASIL. Ministério da Educação. Secretaria de educação Básica. Parâmetros Curriculares de Ensino Médio - PCEM, 2000. Brasília, 2000.

BRASIL. Ministério da Educação. Secretaria de educação Básica. Parecer CEB 15/1998Diretrizes Curriculares Nacionais para o Ensino Médio. Brasília, 1998b.

BRASIL. Ministério da Educação. Secretaria de educação Básica. Parecer 38/2006. Inclusão obrigatória das disciplinas de Filosofia e Sociologia no currículo do Ensino Médio. Brasília, 2006b.

BRASIL. Ministério da Educação. Resolução CEB 03/1998 - Institui as diretrizes Curriculares Nacionais para o Ensino Médio. Brasília, 1998a.

CARVALHO, Lejeune M. G. de (Org.). Sociologia e ensino em debate: experiências e discussão de sociologia no ensino médio. Ijuí: Ed. Unijuí, 2004.

COULSON, M.A.; RIDDEL D. S. Introdução crítica à sociologia. 5. ed. Rio de Janeiro: Zahar, 1979. $143 \mathrm{p}$. 
DEMO, Pedro. Ser professor é cuidar que o aluno aprenda. Porto Alegre: Mediação, 2004. DURKHEIM, Émile. As regras do método sociológico. São Paulo: Martins Fontes, 1995. DURKHEIM, Émile. Educação e Sociologia. 11. ed. São Paulo: Melhoramentos, 1978. ELIAS, N. Introdução à Sociologia. Lisboa: Editora Edições 70, 1999.

FERNANDES, Florestan. A Etnologia e a Sociologia no Brasil. São Paulo: Anhambi, 1958. GIDDENS, A. Em defesa da sociologia. São Paulo: Ed. Unesp, 2001.

GIDDENS, Anthony. Sociologia: uma breve, porém crítica introdução. Rio de Janeiro: Zahar, $1984.136 \mathrm{p}$.

GIDDENS, Anthony. Sociologia. 4. ed. Porto Alegre: Artmed, 2005.

GRAMSCI, A. Concepção dialética da bistória. Rio de Janeiro: Civilização Brasileira, 1978.

GRAMSCI, A. Os intelectuais e a organização da cultura. Rio de Janeiro: Civilização Brasileira, 1982.

IANNI, Octávio. O Ensino das Ciências Sociais no $1^{\circ}$ e $2^{\circ}$ Graus. 1987. Palestra proferida em março de 1985 na Coordenadoria de Estudos e Normas Pedagógicas - CENP/SE.

MARX, Karl. Introduccion general a la crítica de la economia política/1857. 4. ed. Cuadernos Pasado y Presente 1, Córdoba, 1971a.

MARX, Karl. 0 capital. Livro 1, vol.1. 2.ed. Rio de Janeiro: Civilização Brasileira, 1971b. 579 p.

MEKSENAS, Paulo. 0 ensino da sociologia na escola secundária. Leituras e Imagens, p. 67-79.

MEKSENAS, Paulo. Sociologia. 2. ed. São Paulo: Cortez, 1994. 147 p.

MILLS, Wright C. A imaginação sociológica. 2. ed. Rio de Janeiro: Zahar, 1969.

MINAYO, Maria Cecília de Souza. (Org.). Pesquisa social: teoria, método e criatividade. Petrópolis: Vozes, 1994. 80 p.

MORAES, Amaury. Por que sociologia e filosofia no ensino médio?. Sindicato dos Sociólogos do Estado de São Paulo-SINSESP, 1999.

MORAES, Amaury. Licenciatura em ciências sociais e ensino de sociologia: entre o balanço e o relato. Tempo Social-Revista de sociologia da USP, São Paulo, v.15, n. 1, abr. 2003.

NIDELCOFF, Maria Teresa. A escola e a compreensão da realidade. 3. ed. São Paulo: Brasiliense, 1980. 102 p.

NIDELCOFF, Maria Teresa. As ciências sociais na escola. São Paulo, Brasiliense, 1987. 171 p.

OLIVEIRA, Luiz Fernandes de. Sociologia: o conhecimento humano para jovens do ensino técnico-profissionalizante. Rio de Janeiro: IODS, 2004. 197 p.

PEREIRA, Luiza Helena. A sociologia no Ensino Médio no Rio Grande do Sul - Projeto de Pesquisa, registrado na PROPESQ/UFRGS e na FAPERGS/RS, em 2001a.

PEREIRA, Luiza Helena. A Sociologia no Ensino Médio no Rio Grande do Sul - Relatório de Pesquisa, registrado na PROPESQ/UFRGS e na FAPERGS/RS, em 2005a. 
PEREIRA, Luiza Helena. A Sociologia no Ensino Médio no Rio Grande do Sul. Comunicação apresentada aos alunos da Turma U da disciplina HUM 04818, em 22.03.2005b. No prelo

PEREIRA, Luiza Helena. A sociologia no ensino médio. De olho no futuro. Trabalho apresentado no X Congresso Brasileiro de Sociologia, GT Ensino Universitário e Desenvolvimento Científico e Tecnológico, no X Congresso Brasileiro de Sociologia, Fortaleza, setembro de 2001b.

PEREIRA, Luiza Helena. Conbecendo e pensando a sociologia no ensino médio. Comunicação apresentada, na mesa-redonda: "A Sociologia no Ensino Médio e fundamental: realidades locais" por ocasião do V Encontro Nacional de Cursos de Ciências Sociais, realizado nos dias 20 a 23 de julho de 2004, em Niterói - Rio de Janeiro, 2004.

PEREIRA, Luiza Helena. Desafios para o ensino da sociologia no ensino médio. Trabalho apresentado na mesa-redonda Experiências sobre a Docência de Sociologia no Ensino Médio no Brasil, por ocasião do III Encontro Nacional de Cursos de Ciências Sociais, realizado no X Congresso Brasileiro de Sociologia, Fortaleza, setembro de 2001c.

SAVIANI, Dermeval. A nova lei da educação. Campinas: Autores Associados, 1997.

SAVIANI, Dermeval. Comentários sobre o Parecer Diretrizes Nacionais para a organização curricular do ensino médio, de Guiomar Namo de Mello. São Paulo, 1998. Palestra realizada na SE de São Paulo.

TOMAZI, Nelson Dacio et al. Iniciação à sociologia. 2 ed. rev. e ampl. São Paulo: Atual, 2000. $264 \mathrm{p}$.

TOMAZI, Nelson Dacio et al. Sociologia da educação. São Paulo: Atual, 1997. 194 p.

TOMAZI, Nelson Dacio; LOPES JR, Edmilson. Uma trajetória e duas reflexões. In: CARVALHO, Lejeune M. G. de (Org.). Sociologia e ensino em debate: experiências e discussão de sociologia no ensino médio. Ijuí: Ed. Unijuí, 2004.

VALLE, Ione R.; TORNQUIST, Carmen Susana. A sociologia no ensino do $2^{\circ}$ grau: entre 0 cimento armado e a terra fértil. In: Leituras e Imagens, p.11-19.

WEBER, Max. A ética protestante e o espírito do capitalismo. São Paulo: Pioneira, 1967. $233 \mathrm{p}$.

\section{* Textos complementares:}

ADORNO, S. 0 social e a sociologia em uma era de incertezas. Plural: Revista do Programa de Pós-Graduação em Sociologia da USP, São Paulo, n. 4, p. 1-27, 1997,

CALligARIS, Contardo. A adolescência. São Paulo: Publifolha, 2000. (Folha Explica).

CASTRO, Anna Maria de; DIAS, Edmundo. Introdução ao pensamento social. 9. ed. Rio de Janeiro: Eldorado, 1983. 241 p.

CUIN, Charles-Henry; GRESLE, François. História da sociologia. São Paulo: Ensaio, 1994. 299 p.

156 MEDIAÇÕES, LONDRINA, V. 12, N. 1, P. 143-158, JAN/JUN. 2007 
LIBÂNE0, José C. Adeus professor, adeus professora? Novas exigências educacionais e profissão docente. 4. ed. São Paulo: Cortez, 2000. Cap. I, p. 7-53.

MAGR0, Maria Celeste. Estudar também se aprende. São Paulo: EPU, 1979. 194 p.

MARTINS, Carlos. O que é sociologia. 2. ed. São Paulo: Brasiliense, 1982. 98 p. (Coleção Primeiros Passos).

MARTINS, José de Souza. Sobre o modo capitalista de pensar. São Paulo: Hucitec, 1978. 82 p. Cap. 1, 2 e 3.

NIDELCOFF, Maria Teresa. Uma escola para o povo. 3. ed. São Paulo: Brasiliense, 1985. $103 \mathrm{p}$.

PINSKY, Jaime. (Org.). 12 Faces do Preconceito. 4. ed. São Paulo: Contexto, 2001.

VASCONCELLOS, Celso dos S. Para onde vai o professor? Resgate do professor como sujeito de transformação. São Paulo: Libertad, 2003.

WALLERSTEIN, I. O Fim do Mundo como o concebemos. Rio de Janeiro: Editora Revan. 2002.

\section{Para 0 aluno de Ensino Médio}

CELADEC. Como funciona a sociedade? Caxias do Sul: Ed. Paulinas, 1984. 32 p. (Coleção Cadernos de Base; 6).

MARTINS, Carlos. O que é sociologia. 2. ed. São Paulo: Brasiliense, 1982. 98 p. (Coleção Primeiros Passos).

PEREIRA, Raimundo et al. Retrato do Brasil. São Paulo: Política ed. de livros, jornais e revistas Ltda. v. I e II

SANTOS, Jair Ferreira dos. O que é pós-modemismo. 9. ed. São Paulo: Brasiliense, 1991. 111 p. (Coleção Primeiros Passos).

SÃo PAULO. Secretaria de Educação. Coordenadoria de Estudos e Normas Pedagógicas. Proposta Curricular de Sociologia - $2^{\circ}$ grau. 3. ed. São Paulo: SE/CENP, 1990. 58p.

SINGER, Paul. O capitalismo: sua evolução, sua lógica e sua dinâmica. São Paulo: Moderna, 1987.87 p. (Projeto passo à frente. (Coleção Polêmica, 7).

SOUZA, Herbert José de. Como se faz análise de conjuntura. 11. ed. Petrópolis: Vozes, 1991. $54 \mathrm{p}$.

TOMAZI, Nelson Dacio et al. Iniciação à sociologia. 2. ed. rev. e ampl. São Paulo: Atual, 2000

TOMAZI, Nelson Dacio et al. Sociologia da educação. São Paulo, Atual, 1997. 